\title{
Effects of ciprofloxacin on salt marsh sediment microbial communities
}

\author{
Ana Lucía Córdova-Kreylos and Kate M Scow \\ Department of Land, Air and Water Resources, University of California, Davis, CA, USA
}

\begin{abstract}
Fluoroquinolones, a widely used class of antibiotics, are frequently detected in sediments and surface waters. Given their antimicrobial properties, the presence of these compounds may alter the composition of microbial communities and promote antibiotic resistance in the environment. The purpose of this study was to measure sorption, and effects of ciprofloxacin on microbial community composition, in sediment samples from three California salt marshes. Sediments were exposed to a ciprofloxacin concentration gradient $\left(0-200 \mu \mathrm{g} \mathrm{ml}^{-1}\right.$ ciprofloxacin) and microbial community composition characterized using phospholipid fatty acid (PLFA) analysis. Sorption coefficients, expressed as $\log K_{\mathrm{d}}$, were calculated from fits using the Freundlich isotherm model. Ciprofloxacin strongly sorbed to all sediments and had $\log K_{\mathrm{d}}$ values, ranging from 2.9 to 4.3. Clay content was positively $\left(r^{2}=0.98\right)$ and $\mathrm{pH}$ negatively $\left(r^{2}=0.99\right)$ correlated to $K_{\mathrm{d}}$ values. Biomass, PLFA richness, sulfate reducer and Gram-negative bacteria markers increased with ciprofloxacin concentrations, while the $17 \mathrm{cy} / \mathrm{precursor}$ and saturated/unsaturated biomarker ratios, indicators of starvation stress, decreased. The magnitude of the effect of ciprofloxacin on microbial communities was inversely correlated to the degree of sorption to the sediments. Despite the fact that ciprofloxacin is a wide-spectrum antibiotic, its impact on sediment microbial communities was selective and appeared to favor sulfate-reducing bacteria and Gram-negative bacteria.
\end{abstract}

The ISME Journal (2007) 1, 585-595; doi:10.1038/ismej.2007.71; published online 6 September 2007

Subject Category: microbial population and community ecology

Keywords: ciprofloxacin; salt marsh; PLFA; sorption; sulfate reducers

\section{Introduction}

There has been concern for decades about potential ecological impacts of pharmaceuticals, but only recently have advances in analytical chemistry permitted detection of these chemicals at the concentrations typically found in the environment (Halling-Sørensen et al., 1998; Zuccato et al., 2000; Bila and Dezotti, 2003; Boyd et al., 2003). Antibiotics reach the environment through intentional disposal of surplus drugs to sewage, release to sewage through urine and feces, leaching from landfills and discharges from sewage treatment plants or confined animal farming operations (Daughton and Ternes, 1999; Daughton, 2000).

One frequently detected class of antibiotics in the environment is the fluoroquinolones, compounds inhibiting both Gram-positive (GP) and Gram-negative (GN) bacteria, and commonly used to treat tuberculosis, digestive and urinary tract infections and anthrax. The mode of action of these compounds is to interfere with DNA synthesis by

Correspondence: AL Córdova-Kreylos, Department of LAWR, University of California, 1110 PES Building, One Shields Avenue, Davis, CA 95616, USA.

E-mail: anacordova@ucdavis.edu

Received 11 May 2007; revised 23 July 2007; accepted 23 July 2007; published online 6 September 2007 binding to DNA gyrase and thus preventing replication (Fernandes, 1988; Hooper, 1999). Ciprofloxacin and levofloxacin account for $65 \%$ of the total fluoroquinolone use and represent 3.3 billion dollars in global sales (Datamonitor Strategic Report, 2004). In a dose of ciprofloxacin ingested, an estimated $45 \%-62 \%$ is excreted unmetabolized in human urine and $15 \%-25 \%$ in feces (Golet et al., 2003). Environmental risk studies have estimated environmental loadings of ciprofloxacin from European sewage treatment plants to be as high as 186.2 tones per year in 1999 (Halling-Sorensen, 2000).

Monitoring surveys have detected antibiotics in aquatic ecosystems ranging from $\mathrm{ngl}^{-1}$ to $\mathrm{mgl}^{-1}$ concentrations (Giger et al., 2003). In the United States, 22 antibiotics and antimicrobial compounds were detected in $50 \%$ of the water samples from streams influenced by urbanized areas and livestock activities across the country, and $2.6 \%$ tested positive for ciprofloxacin with a maximum concentration of $0.030 \mu \mathrm{gl}^{-1}$ (Kolpin et al., 2002). Other studies have reported ciprofloxacin at concentrations of $118-400 \mathrm{ng} \mathrm{l}^{-1}$ in Canadian wastewater treatment effluents (Miao et al., 2004), and 100$160 \mathrm{ng} \mathrm{l}^{-1}$ in secondary effluents from municipal wastewater treatment plants in Arizona, California and Georgia (Renew and Huang, 2004). 
Fluoroquinolones are strongly sorbed to organic matter (MacKay et al., 2004; MacKay and Figueroa, 2004) and clays (Nowara et al., 1997; Seremet and MacKay, 2003) with partition coefficients ranging from $\log K_{\mathrm{d}}=2.45$ to 2.69 for pure clays and $\log K_{\mathrm{oc}}$ up to 4.85 (Nowara et al., 1997). In one of few studies measuring ciprofloxacin associated with solid as well as aqueous samples, sludge solids in a Swiss wastewater treatment plant contained an average of $2.2 \mathrm{mgl}^{-1}$, more than three orders of magnitude higher than the mean concentration of $0.427 \mu \mathrm{g} \mathrm{l}^{-1}$ in the raw sewage-filtered effluent (Golet et al., 2003). Several studies on ciprofloxacin sorption to clays and minerals have been published (Seremet and MacKay, 2003; Gu and Karthikeyan, 2005), but there is no published data on sorption of ciprofloxacin to soil or sediments. However, based on the behavior of compounds similar in chemical structure, aqueous samples may grossly underestimate the presence of ciprofloxacin in the environment.

Salt marshes are destinations for many pollutants and nutrients, many of which are filtered out of surface waters, before they enter the ocean. Because antibiotics are designed specifically to target microorganisms, the persistence of these compounds in sediments may negatively impact estuarine microbial processes. Surprisingly, little research has addressed the effects of ciprofloxacin and other antibiotics on microbial communities in natural ecosystems. Ciprofloxacin has been shown to negatively affect freshwater algae communities by decreasing species richness in microcosm studies at concentrations as low as $0.015 \mu \mathrm{gl}^{-1}$ (Wilson et al., 2003). What are lacking are controlled studies to determine what concentrations of ciprofloxacin cause changes in sediment microbial community structure and function.

We hypothesized that microbial community composition, biomass and richness are modified by ciprofloxacin at concentrations found in the environment, and that sorption plays an important role in controlling the magnitude of these effects. For this purpose, sediments from three California salt marshes were used to determine sorption coefficients of ciprofloxacin and to determine the effects of the antibiotic on the phospholipid fatty acid (PLFA) fingerprint of the sediment microbial community. This study is part of a larger project, the Pacific Estuarine Ecosystem Indicator Research (PEEIR) Consortium, within the EPA's EaGLe's Program, that aims to develop indicators of toxicant-induced stress and bioavailability for wetland biota.

\section{Materials and methods}

Site selection and sediment sampling

Sediments were collected in the summer of 2003 from three salt marshes in the San Francisco Bay area: Stege Marsh (SM), Walker Creek (WC) and China Camp (CC). Both CC and SM are located directly in the San Francisco Bay; WC is one of the main tributaries leading into Tomales Bay. Dominant plant species include Spartina and Salicornia in all the sites. SM is highly contaminated with metals, pesticides and organic solvents (Hwang et al., 2006a, b) and has been targeted for remediation by the Superfund program. WC has high levels of mercury and CC is a relatively unpolluted site. More detailed descriptions of the sampling sites can be found elsewhere (Córdova-Kreylos et al., 2006; Hwang et al., 2006a, b). Several cores were collected from different locations within each salt marsh using a 2.5-cm diameter Teflon corer to a depth of $5 \mathrm{~cm}$. The cores were pooled together and homogenized in sterile glass jars. They were transported in ice and stored at $4{ }^{\circ} \mathrm{C}$ in a cold room until the experiments were started. For sorption experiments, samples were air-dried, sieved through a $2 \mathrm{~mm}$ mesh to ensure uniform mass in the experiments and stored dry in glass jars.

\section{Sediment characterization}

Sediments were characterized for $\mathrm{pH}$, cation exchange capacity, organic carbon content, total nitrogen content and texture. Cation exchange capacity was determined by the compulsive exchange method and $\mathrm{pH}$ was measured using a gel $\mathrm{pH}$ electrode connected to a $\mathrm{pH}$ meter (Orion, Waltham, MA, USA) as described in the Standard Methods of the Soil Science Society of America (SSSA) for soil analysis (Sparks, 1996). Texture was determined by particle size distribution analysis with laser diffraction using a Beckman-Coulter LS-230 (BeckmanCoulter, Miami, FL, USA) with a $750 \mathrm{~nm}$ laser beam detection as described previously (Eshel et al., 2004). Carbon and nitrogen were determined by micro-Dumas combustion using a $\mathrm{C} / \mathrm{N}$ analyzer (Carlo Erba; Milan, Italy).

\section{Sorption experiments}

Sorption experiments were performed according to EPA standard procedures as described by Figueroa et al. (2004). A preliminary sorption experiment was performed for each sediment type to determine the optimum sediment/solution ratio and incubation time required to reach the equilibrium concentrations in solution. To inhibit biodegradation, sodium azide was added at $1 \%$ of the sediment mass. Sorption curves were created with 12 ciprofloxacin (Sigma-Aldrich, St Louis, MO, USA) concentrations ranging from 0.5 to $100 \mu \mathrm{g} \mathrm{ml}^{-1}$ in a $0.01 \mathrm{M} \mathrm{CaCl}_{2}$ solution. After equilibration the sediment was separated from the aqueous phase by centrifugation at $8000 \mathrm{~g}$ for $15 \mathrm{~min}$. The aqueous solution was analyzed with a Perkin Elmer Series 2 liquid chromatograph (LC) connected to an ultraviolet diode array (DA) detector (SPD M10A, Shimadzu). 
The LC-DA system was operated under the following conditions: column, Alltech Econosphere C18, $5 \mu \mathrm{m}, 250 \times 4 \mathrm{~mm}$, eluent, phosphate buffer $(30 \mathrm{mM}$ $\mathrm{KH}_{2} \mathrm{PO}_{4}, 10 \mathrm{mg} \mathrm{l}^{-1}$ tri-ethylamine, adjusted to $\mathrm{pH}$ $3 \pm 0.01$ )/acetonitrile, 70:30; flow rate, $1.5 \mathrm{ml} \mathrm{min}^{-1}$; injection, $20 \mu \mathrm{l}$; detection, ultraviolet $280 \mathrm{~nm}$. Under these conditions, the retention time for ciprofloxacin was $3.2 \mathrm{~min}$ and the detection limit, $0.5 \mu \mathrm{g} \mathrm{ml}^{-1}$. The amount of ciprofloxacin sorbed was calculated from the difference between the original and final aqueous concentrations. The results were expressed as mass sorbed to the sediment $\left(C_{\mathrm{s}}\right)$ in $\mathrm{mg} \mathrm{kg}^{-1}$ and concentration remaining in solution $\left(C_{\mathrm{e}}\right)$ in $\mu \mathrm{g} \mathrm{ml}^{-1}$. The data obtained were fitted to the linear form of the Freundlich equation $\left(\log C_{\mathrm{s}}=\log K_{\mathrm{d}}+n \log C_{\mathrm{e}}\right.$ ), and $\log K_{\mathrm{d}}$ obtained from the slope of the linear regression of the points. Sorption coefficients were normalized for organic carbon using the equation $K_{\mathrm{oc}}=K_{\mathrm{d}} / f_{\mathrm{oc}}$, where $f_{\mathrm{oc}}$ is the organic carbon fraction in each sediment.

\section{Microcosm exposure experiment}

Sediments were exposed to ciprofloxacin concentrations ranging from 0.02 to $200 \mu \mathrm{g} \mathrm{ml}^{-1}$. The exposure was performed in microcosms made out of $60 \mathrm{ml}$ glass serum bottles outfitted with thick butyl stoppers and aluminum seals. Each bottle contained $20 \mathrm{~g}$ of sediment and $40 \mathrm{ml}$ of mineral media (per liter: $5 \mathrm{~g} \mathrm{NaCl}, 1.5 \mathrm{~g} \mathrm{KH}_{2} \mathrm{PO}_{4}, 5 \mathrm{~g} \mathrm{NH} \mathrm{N}_{4} \mathrm{Cl}$, $1 \mathrm{~g} \mathrm{MgCl}_{2}$ and $1 \mathrm{~g} \mathrm{CaCl}_{2}$ ) amended with the antibiotic and $20 \mathrm{mM} \mathrm{Na}_{2} \mathrm{SO}_{4}$. The only carbon source was ciprofloxacin and the carbon present in the sediment slurries. The microcosms were flushed with nitrogen gas and the final $\mathrm{CO}_{2}$ concentration in the headspace was adjusted to $20 \%$. The microcosms were incubated in the dark for 30 days. Triplicate controls that were not autoclaved and contained no ciprofloxacin were also incubated. At the end of the incubation period, the contents of the bottles were centrifuged at $3000 \mathrm{~g}$ for $15 \mathrm{~min}$ and sediment collected for PLFA analysis.

\section{PLFA analysis and nomenclature}

Sediment microbial community composition was determined using PLFA analysis as described previously (Bossio and Scow, 1998). Briefly, frozen $\left(-80^{\circ} \mathrm{C}\right)$ sediment samples were freeze-dried and $8 \mathrm{~g}$ of dry sediment were used for the lipid extraction. Lipids were extracted using a one-phase chloroform/methanol/phosphate-buffered solvent. Phospholipids were separated from nonpolar lipids and converted into fatty acid methyl esters prior analysis. Quantification was performed using a Hewlett Packard 6890 Gas Chromatograph fitted with a $25 \mathrm{~m}$ Ultra 2 (5\% phenyl)-methylopolysiloxane column (J\&W Scientific, Folsom, CA, USA). Identification was performed using bacterial fatty acid standards and software from the MIS Microbial Identification System (Microbial ID Inc., Newark, DE, USA).
Lipids were named following the accepted convention (for example, A:B $\omega \mathrm{C}$ ) as described by Bossio and Scow (1998).

Total microbial biomass was calculated by summing the mass of all detected fatty acids (White et al., 1979; Frostegard et al., 1991; Bossio et al., 1998) and expressed as nanomoles of PLFA per gram of dry sediment. The number of different PLFAs detected in each sample was used as a measure of richness. In addition, the following biomarkers and ratios were detected or calculated: sulfate-reducer bacteria (SRB) (br17:1 for Desulfovibrio, 10Me16:0 for Desulfobacter and 17:1 for Desulfobulbus); eukaryotes (polyunsaturated PLFAs); Gram-positives (branched PLFAs); Gram-negatives (monoun-

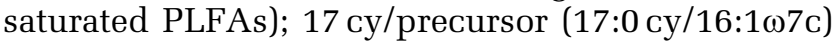
and saturated/unsaturated (sat/unsat) PLFAs.

\section{Statistical analysis}

Correspondence analysis was performed using the CANOCO software (Version 4.0, Microcomputer Power, Ithaca, NY, USA). Fatty acid concentrations were expressed as nmol g ${ }^{-1}$ of dry sediment for the analysis. All PLFA detected and named were used for the multivariate analysis. Correspondence analysis plots constructed in SigmaPlot V. 8.02 (SPSS Inc., 2002) were used to evaluate and compare PLFA fingerprints across microbial communities from different marshes and different ciprofloxacin concentrations. Correspondence analysis was selected because the PLFA data set contains both nominal and zero values. Total PLFA biomass, richness and biomarkers for different ciprofloxacin concentrations in each sediment were compared by one-way analysis of variance (or analysis of variance by ranks when data failed the normality test), and the HolmSidak multiple comparisons test using SigmaStat (SPSS Inc., 2002). Differences were determined statistically significant if $P<0.05$.

\section{Results}

Characterization of test sediments

Sediment samples varied in $\mathrm{pH}$, cation exchange capacity, clay content, total nitrogen and organic carbon (Table 1). Organic carbon ranged from 1.3\% to $2.8 \%$ with varying $\mathrm{C} / \mathrm{N}$ ratios $(8.86-14.05)$. $\mathrm{SM}$ had the highest clay content, whereas both WC and CC sediments were high in sand content. Only SM, the most polluted site, had an acidic $\mathrm{pH}$ (5.11) and the highest cation exchange capacity.

\section{Sorption experiments}

Sorption data for all sediments showed good fit to the Freundlich sorption model $\left(r^{2}=0.91-0.96\right)$ (Table 2). The Freundlich model was thus used to evaluate relationships between sediment properties and sorption. To facilitate comparisons between sediments, all fits were considered to approximate 
Table 1 Physical and chemical properties of the estuarine sediments used in this study. Averages \pm s.e.

\begin{tabular}{lccc}
\hline Property & Stege Marsh & Walker Creek & China Camp \\
\hline pH & $5.1 \pm 0.1$ & $7.8 \pm 0.1$ & $8.6 \pm 0.1$ \\
CEC $\left(\mathrm{cmol} \mathrm{kg}^{-1}\right)$ & 11.14 & 5.08 & 7.28 \\
& & & \\
Texture & & 43.9 & 56.2 \\
\% Sand & 26.5 & 48.5 & 38.7 \\
\% Silt & 60.7 & 7.6 & 5.1 \\
\%Clay & 12.8 & & \\
Total N & & $0.20 \pm 0.06$ & $0.22 \pm 0.12$ \\
\% dws & $0.20 \pm 0.09$ & & \\
Org C & & $1.99 \pm 0.03$ & $2.44 \pm 0.07$ \\
$\%$ dws & $2.81 \pm 0.05$ & & \\
\hline
\end{tabular}

Abbreviation: dws, dry weight sediment.

Table 2 Freundlich model equations, sorption coefficients and fits of ciprofloxacin in salt marsh sediments

\begin{tabular}{lcccc}
\hline Sediments & $\mathrm{n} \pm$ s.e. & $\log \mathrm{K}_{d} \pm$ s.e. & P-value & $\mathrm{r}^{2}$ \\
\hline Stege Marsh & $0.81 \pm 0.09$ & $4.27 \pm 0.04$ & $<0.001$ & 0.91 \\
Walker Creek & $1.14 \pm 0.08$ & $3.20 \pm 0.07$ & $<0.001$ & 0.95 \\
China Camp & $1.06 \pm 0.07$ & $2.90 \pm 0.07$ & $<0.001$ & 0.96
\end{tabular}

The linear from of the Freundlich equation was used: $\log C_{\mathrm{s}}=$ $n \log C_{\mathrm{e}}+\log K_{\mathrm{d}}$.

linearity $(n \sim 1)$. Sorption was strongest in SM $\left(\log K_{\mathrm{d}}=4.27\right)$, followed by WC $\left(\log K_{\mathrm{d}}=3.20\right)$ and CC $\left(\log K_{\mathrm{d}}=2.90\right)$. Because only three points were used for regression, only apparent correlations could be determined. The \%OC was positively correlated with $\log K_{\mathrm{d}}\left(r^{2}=0.67\right)$, as was clay content $\left(r^{2}=0.98\right)$. $\log K_{\mathrm{oc}}$ was positively correlated with clay content $\left(r^{2}=0.79\right)$. SM, the sediment with the highest clay content $(12.8 \%)$, had the highest sorption coefficient, followed by WC and CC sediments, containing $7.6 \%$ and $5.1 \%$ clay, respectively. The sorption coefficients and sediment $\mathrm{pH}$ values had a strong negative correlation $\left(r^{2}=0.99\right)$.

\section{Microbial community composition}

A total of 79 different PLFAs were detected across all sediments, specifically 75, 58 and 55 lipids were detected in WC, CC and SM, respectively. On the basis of a correspondence analysis of all sediments (Figure 1), untreated controls and lower ciprofloxacin concentration treatments grouped together on the right side of the first axis in two clusters, whereas all other samples with higher ciprofloxacin concentrations grouped to the left (Figure 1). Overall, the first axis appeared to be related to ciprofloxacin concentrations, and the second axis to $K_{\mathrm{d}}$. Saturated PLFA tended to be more abundant at lower ciprofloxacin concentrations and unsaturated
PLFAs were associated with higher ciprofloxacin concentrations (Figure 1, lipid plot).

In correspondence analyses performed on each sediment independently, the variation explained on the first two axes decreased (from $85.2 \%$ in CC to $69.1 \%$ in SM) with increasing sorption capacity of the sediments. In CC microcosms, the $0.02 \mu \mathrm{g} \mathrm{ml}^{-1}$ treatments grouped closely with the control samples. The higher concentration treatments formed a tight cluster to the left side of the plot. For the WC sediments, the 0.02 and $0.2 \mu \mathrm{g} \mathrm{ml}^{-1}$ treatments grouped in the center of the first axis, and the higher treatments to the left. For the SM sediments, the treatments were loosely clustered and less separated along the first axis. Associations were also observed in plots of individual sediments between saturated PLFAs and controls and low ciprofloxacin concentrations, and between unsaturated PLFAs and higher ciprofloxacin concentrations (Figure 2).

\section{Biomass and richness}

The total PLFA content for the controls ranged from $8.4 \pm 0.3$ to $11.6 \mathrm{nmol} \mathrm{g}^{-1}$ dry sediment (Table 3 ). In all three sediments, biomass increased with higher ciprofloxacin concentrations although the magnitude of increase varied by sediment. CC had the largest net increase of biomass, with the highest ciprofloxacin treatment having triple the biomass of the control values (Table 3). Biomass differences between the control and the $200 \mu \mathrm{g} \mathrm{ml}^{-1}$ treatments were significant in all sediments, except in SM.

Phospholipid fatty acid richness, estimated from the number of peaks detected, also increased at higher ciprofloxacin concentrations. The average total number of PLFAs detected in control samples of all sediments ranged from 25 to 31 . Peak numbers increased by at least $50 \%$ in CC and WC sediments when ciprofloxacin concentrations were $2 \mu \mathrm{g} \mathrm{ml}^{-1}$ or higher (Table 3). The most significant increase compared to controls was observed in WC's $2.0 \mu \mathrm{g} \mathrm{ml}^{-1}$ treatment, followed by CC's $200 \mu \mathrm{g} \mathrm{ml}^{-1}$ treatment, whereas changes in SM were not statistically significant.

\section{Biomarkers}

Phospholipid fatty acid biomarkers representative of specific microbial groups, such as those associated with SRB were dramatically affected by the addition of ciprofloxacin. All sediment controls had a similar SRB abundance and specific biomarkers for Desulfobacter and Desulfobulbus, but not Desulfovibrio, were present. Addition of $0.2,2,100$ and $200 \mu \mathrm{g} \mathrm{ml}^{-1}$ of ciprofloxacin significantly increased SRB biomass in all sediments (Figure 3). Part of the increase was due to enrichment of Desulfovibrio biomarkers, which in the $200 \mu \mathrm{g} \mathrm{ml}^{-1}$ treatments accounted for approximately $10 \%$ in SM and $20 \%$ in CM and WC of the SRB biomass. In SM, Desulfobulbus bio- 

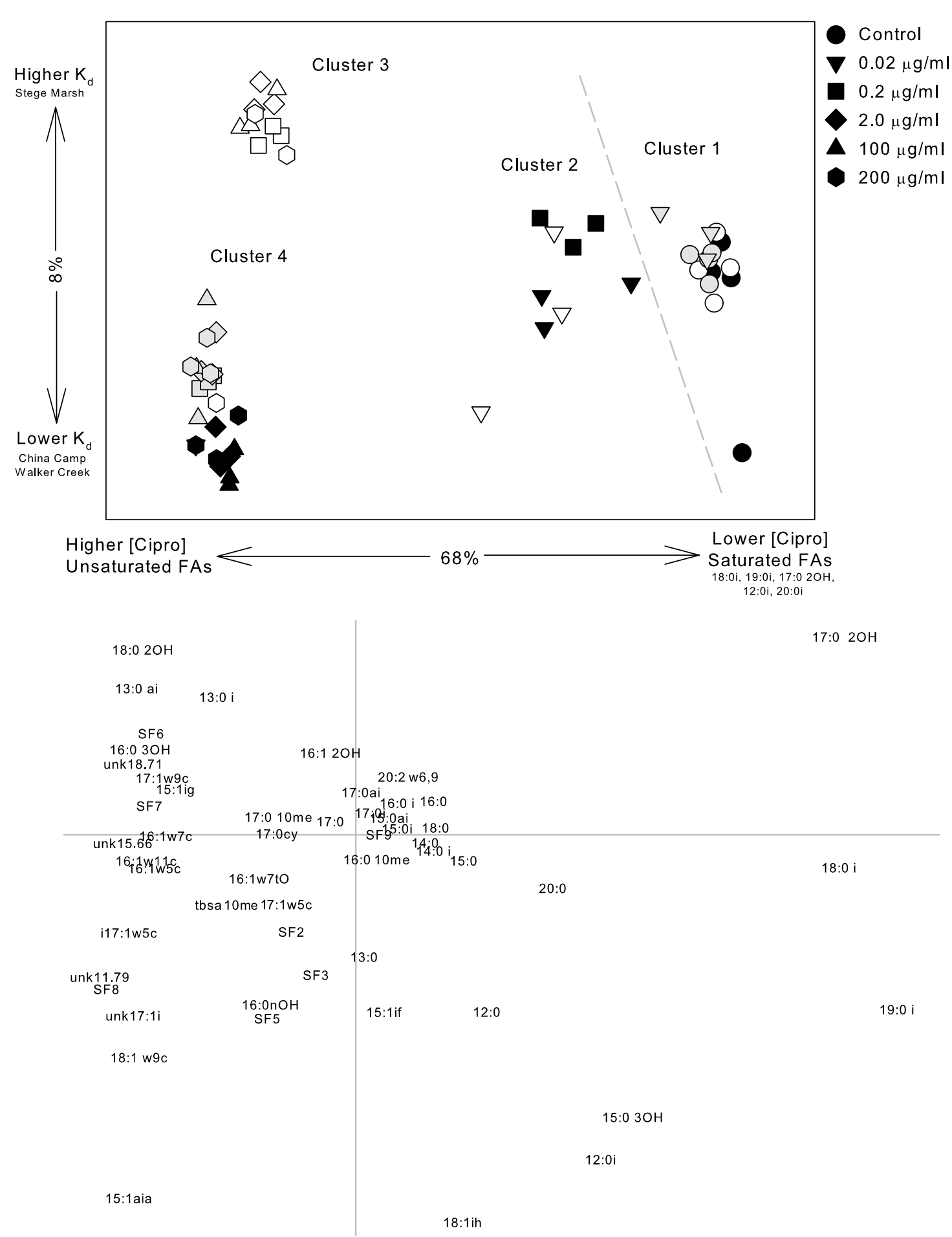

Figure 1 Ordination plot of CA results for China Camp (gray symbols), Walker Creek (black symbols) and Stege Marsh (white symbols) with the corresponding PLFA scores plot. CA was performed for all sediment and all antibiotic concentrations. PLFA labeled as unk, indicate an unnamed peak, SF indicates a group of unresolved peaks. SF2 includes 15:1 iso I and h/13:0 3OH; SF3 includes 12:0 alde/ uknown 10.928/14:0 3OH/16:1 iso I; SF5 includes 17:1 anteiso B/iso I; SF 6 18:0 anteiso/18:2w6,9c; SF 7 18:1w12t/w9t/w7t/18:1w7c/ w9t/w12t/18:1w9c/w12t/w7c; SF8 includes unknown 18.756/19:1w11c/19:1; and SF9 includes unk 18:846/unk 18.858/19:0cy w10c CA, correspondence analysis; PLFA, phospholipid fatty acid.

markers dominated at the highest ciprofloxacin concentrations (Figure 3). In WC and CC, Desulfovibrio and Desulfobulbus increased in abundance at higher ciprofloxacin concentrations, but their relative abundance was very similar to Desulfobacter biomarkers. The ratio of GN (monoenoic fatty acids) to GP biomarkers (branched fatty acids) indicated that GP were more abundant in controls and the low 

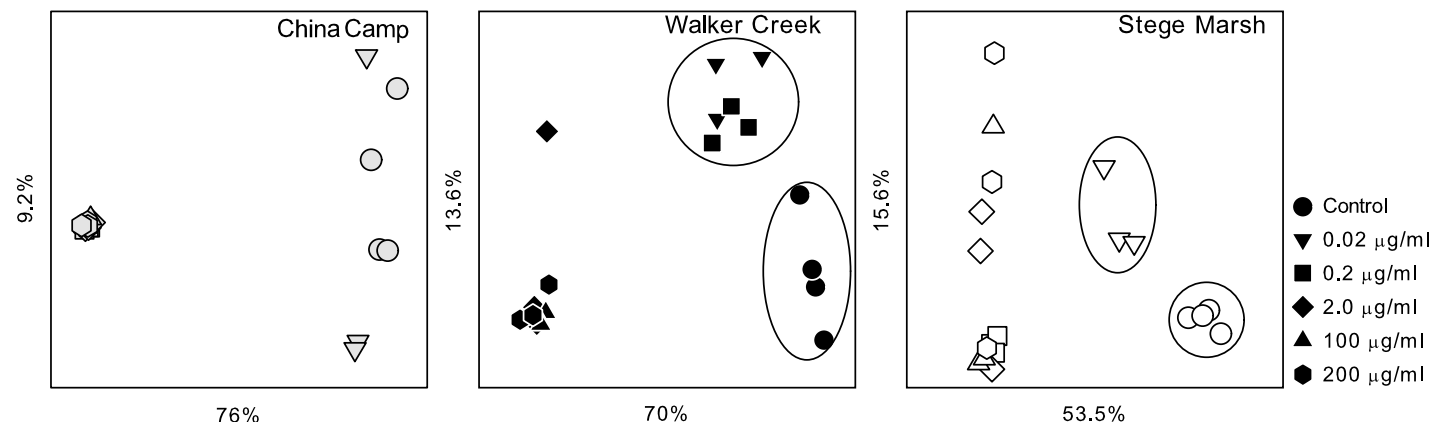

Figure 2 Ordination plot of CA results for individual sediment microbial communities. Symbols correspond to different ciprofloxacin concentrations as detailed in Figure 1. CA, correspondence analysis; PLFA, phospholipid fatty acid.

Table 3 PLFA biomass (nmolg ${ }^{-1}$ dry sediment) and richness (number of PLFA) across ciprofloxacin concentrations in the three estuarine sediments tested

\begin{tabular}{|c|c|c|c|c|c|c|}
\hline \multirow[t]{2}{*}{ Cipro $\left(\mu \mathrm{g} \mathrm{ml^{-1 }}\right)$} & \multicolumn{2}{|c|}{ China Camp } & \multicolumn{2}{|c|}{ Walker Creek } & \multicolumn{2}{|c|}{ Stege Marsh } \\
\hline & Biomass & Richness & Biomass & Richness & Biomass & Richness $^{\mathrm{a}}$ \\
\hline 0.0 & $8.4(0.3)^{\mathrm{b}}$ & $27.5(2.5)^{\mathrm{b}}$ & $11.6^{\mathrm{c}}$ & $31^{\mathrm{b}}$ & $8.6(1.3)^{\mathrm{c}}$ & $25.0(2.0)$ \\
\hline 0.02 & $6.2(1.3)^{\mathrm{b}}$ & $23.3(0.9)^{\mathrm{b}}$ & $7.4(0.9)^{\mathrm{c}}$ & $26.3(1.2)^{\mathrm{b}}$ & $16.0(1.4)$ & $32.3(4.1)$ \\
\hline 0.2 & $25.3(2.5)^{\mathrm{c}}$ & $43(1.5)^{\mathrm{c}}$ & $11.1(1.0)^{\mathrm{c}}$ & $29.7(1.5)^{\mathrm{b}}$ & $12.9(0.7)$ & $29.7(0.9)$ \\
\hline 2.0 & $24.8(1.9)^{\mathrm{c}}$ & $42.7(1.9)^{\mathrm{c}}$ & $24.3(0.7)^{\mathrm{b}}$ & $48.7(0.9)^{\mathrm{c}}$ & $17.4(2.7)$ & $37.0(1.2)$ \\
\hline 100 & $25.8(4.4)^{\mathrm{c}}$ & $42.3(2.7)^{\mathrm{c}}$ & $20.2(3.1)^{\mathrm{b}}$ & $43.7(3.3)^{\mathrm{c}}$ & $19.3(2.4)^{\mathrm{b}}$ & $35.0(5.5)$ \\
\hline 200 & $23.8(1.5)^{\mathrm{c}}$ & $44.7(0.9)^{\mathrm{c}}$ & $17.8(2.4)^{\mathrm{b}}$ & $40.0(1.2)^{\mathrm{c}}$ & $12.3(0.6)$ & $32.0(1.7)$ \\
\hline
\end{tabular}

Averages are provided with s.e. in parentheses. Different letters indicate significant differences between means as determined by ANOVA (by ranks when normality test failed) and the Holm-Sidak multiple comparison method. Bold entries indicate the treatment with the highest statistically significant difference versus corresponding control in that particular sediment.

${ }^{a}$ No significant differences were found among means.

ciprofloxacin concentration treatments. At higher ciprofloxacin concentrations, GN were the predominant group. Ratios of GN/GP ranged from 0.01 to 0.02 in all control sediments, but increased up to 1.4 at the highest ciprofloxacin concentrations in all sediments.

Two biomarkers of stress were evaluated in all the microbial communities: 17:0 cy per precursor and sat/unsat PLFAs. The ratio of 17:0 cy per precursor was $<1$ in all sediments treated with ciprofloxacin, with the exception of CC at $0.02 \mu \mathrm{g} \mathrm{ml}^{-1}$, where the ratio was close to 3 . All control microcosms had 17 cy per precursor ratios above 2, and as high as 4 for the control in CC sediment. Control microcosms had sat/unsat ratio above 10 and as high as 20 (SM), while all ciprofloxacin-treated microcosms had sat/unsat ratios below 5 (Figure 4).

\section{Discussion}

The sorption coefficients obtained in this study $\left(\log K_{\mathrm{d}}=2.90-4.27\right)$ were comparable to those obtained by other groups in batch experiments for ciprofloxacin and similar compounds. $\log K_{\mathrm{d}}$ coefficients ranged from 2.69 to 3.75 for enrofloxacin (with a similar chemical structure to ciprofloxacin) in a variety of soils (Seremet and MacKay, 2003). A $\log K_{\mathrm{d}}$ of 2.62 was reported for ciprofloxacin sorption in sewage sludge with $\mathrm{pH}$ of 6.5 (Giger et al., 2003), and a $\log K_{\mathrm{d}}$ of 4.29 was reported for similar sludge with $\mathrm{pH}$ 7.5-8.4 (Golet et al., 2003). In our sediments, higher $\mathrm{pH}$ values were associated with lower sorption coefficients (data not shown). Sorption is expected to be $\mathrm{pH}$ sensitive because ciprofloxacin speciation is $\mathrm{pH}$ dependent (Lin et al., 2004). A review reported $\log K_{\text {ос }}$ values for fluoroquinolones on sewage sludge and soils (loamy sand, clay and loam) ranging from 3.05 to 5.88 (Rao et al., 1993), similar to our obtained values of 4.51-5.82. In our experiments, $\log K_{\mathrm{oc}}$ was positively correlated with clay content $\left(r^{2}=0.79\right)$, but not correlated to organic carbon content. This lack of correlation has been reported by other groups, indicating the limitations of carbon-normalized coefficients in explaining sorption of antibiotics in soils (Tolls, 2001).

Because ciprofloxacin is a broad-spectrum antibiotic, we expected reduced biomass and numbers of PLFAs in the exposed sediment microbial communities. We also expected selective effects of the antibiotic; in clinical trials ciprofloxacin showed higher bactericidal activity against GN than GP bacteria (Cunha et al., 1997; Dalhoff and Schmitz, 2003; Berlanga et al., 2004). In contrast, both biomass and PLFA numbers increased in ciproflox- 

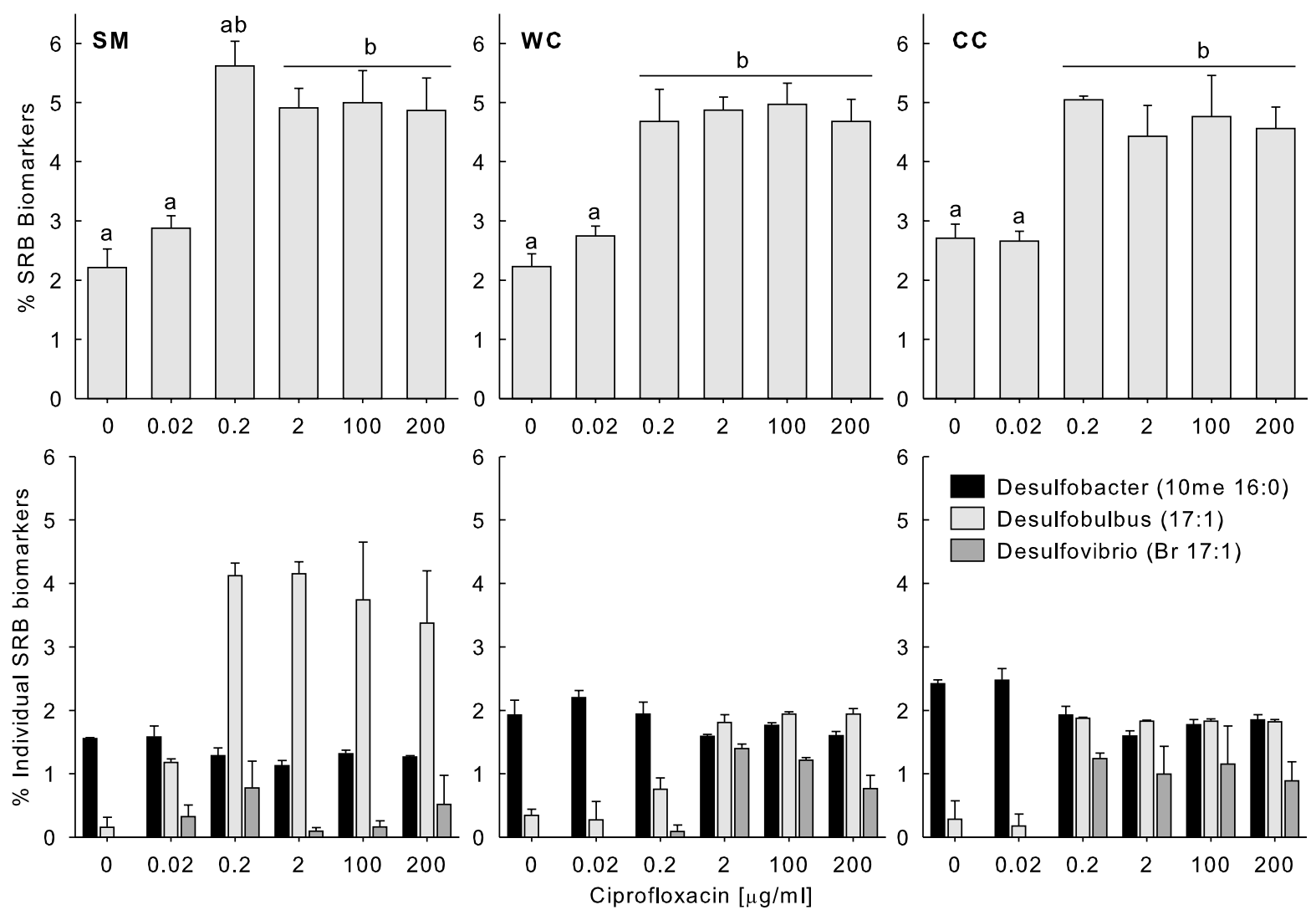

Figure 3 Sulfate reducer biomarkers. Upper panel shows the percent abundance of all SRB biomarkers. Bottom panel shows the individual contribution of each biomarker group to the total biomass. Different letters above the bars indicate significant differences, as determined by ANOVA and the Holm-Sidak multiple comparison test. ANOVA, analysis of variance; SRB, sulfate-reducer bacteria.

acin-treated microcosms, and GN biomarkers were higher than GP biomarkers in treated microcosm. The lack of antibiotic activity we observed in anaerobic sediment microcosms is consistent with reports of delayed, diminished, or lack of antibiotic activity against infections involving anaerobic bacteria (Lewin et al., 1991; Zabinski et al., 1995; Morrissey and George, 2001; Stein and Goldstein, 2006). All these studies have been performed on clinical isolates and pure cultures, but there is no reason to expect that soil microbes would behave differently. Our results suggest that ciprofloxacin has a significant decrease or complete loss of antibiotic activity in anaerobic sediments.

Substantial increases in microbial biomass observed in CC and WC sediments, may be due to the use of ciprofloxacin as a carbon source by some of the sediment bacteria. However, confirmation of ciprofloxacin biodegradation would require measurement of chemical disappearance, which was beyond the scope of this study. In both sediments, biomass appeared to have leveled off or slightly declined at the highest ciprofloxacin concentrations. In contrast, microbial biomass was insensitive to ciprofloxacin concentration in SM, the sediment with the greatest sorption capacity. Another indicator of higher carbon availability in ciprofloxacintreated sediments is the $17 \mathrm{cy}$ per precursor ratio.
The 17 cy per precursor ratio was two to three times higher in controls than in treated microcosms in all sediments. Increased ratios of $17 \mathrm{cy}$ per precursor have been linked to starvation (Kieft et al., 1994, 1997; Bossio et al., 1998), providing additional support for the hypothesis that more carbon was available to the enriched microbial populations (those showing up in PLFA analysis) (in the higher than in the lower ciprofloxacin treatments). Another supporting result is the elevated sat/unsat ratios observed in control and $0.2 \mu \mathrm{g} \mathrm{ml}^{-1}$ CC treatment. Increased sat/unsat ratios have been observed in microbial communities under starvation stress (Bossio et al., 1998), but also in those exposed to solvents (Ramos et al., 2002), and after entering stationary phase (Kieft et al., 1994, 1997).

The SRB biomarkers used in this study targeted Desulfobacter, Desulfobulbus and Desulfovibrio, all are GN SRB grouped in the $\delta$-Proteobacteria (Macalady et al., 2000; Rabus et al., 2006). Despite their grouping, these genera differ in their metabolic versatility when it comes to carbon substrates. Desulfovibrio are part of the Desulfovibrionaceae family and are characterized by the incomplete oxidation of carbon substrates with the production of acetate (Rabus et al., 2006). Desulfovibrio, originally considered metabolically specialized, has been recently shown to be able to utilize $\mathrm{H}_{2}$, 

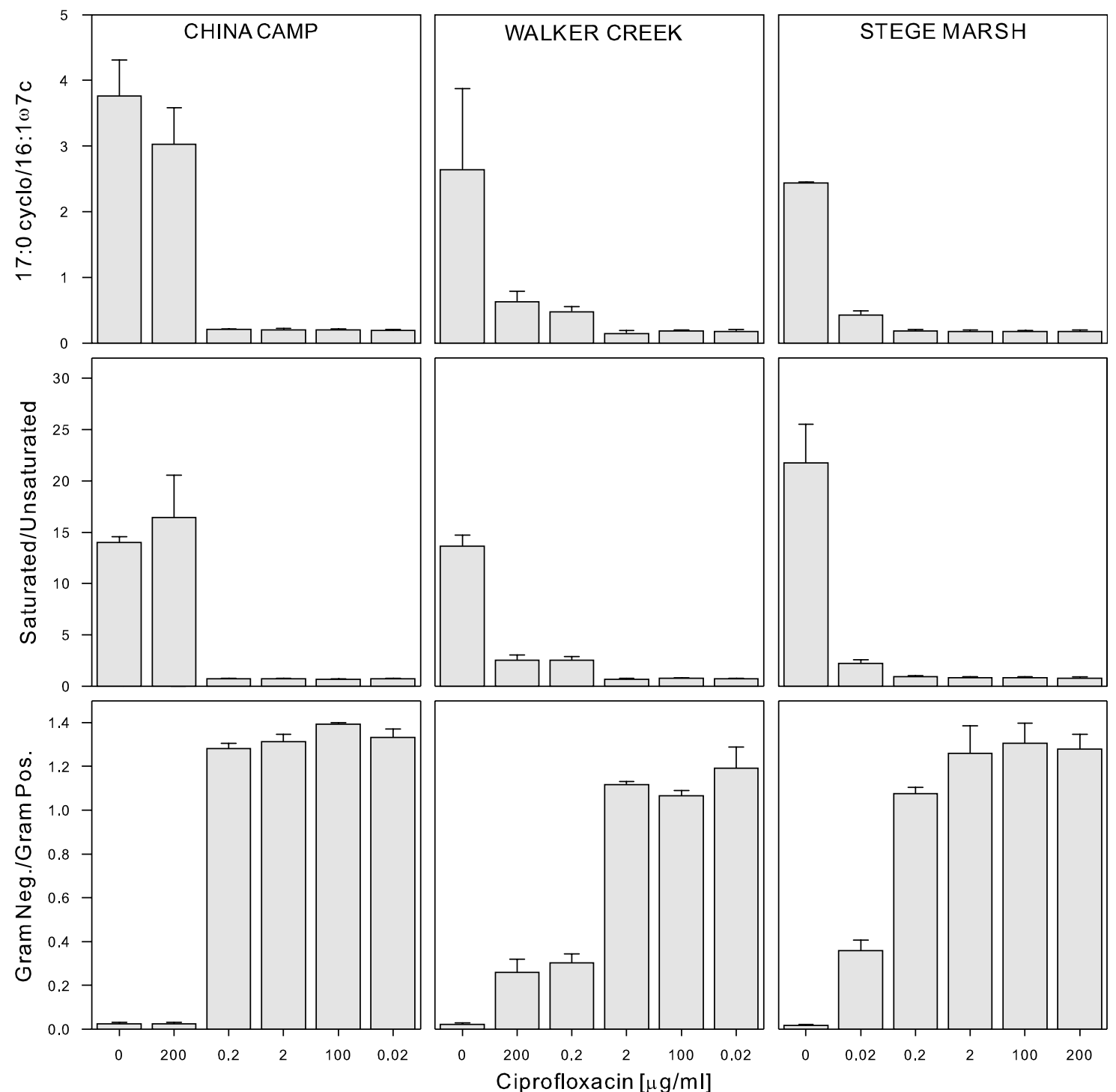

Figure 4 Stress biomarker ratios and Gram-positive/Gram-negative biomarker abundance. Bars indicate averaged with s.e.

formate, lactate and crude oil components. Desulfobulbus, part of the Desulfobulbaceae, are complete acetate oxidizers with a very versatile carbon metabolism (Rabus et al., 2006). Desulfobacter belong to the Desulfobacteriaceae family, are incomplete acetate oxidizers with a limited carbon metabolism that uses acetate as a carbon source almost exclusively (Rabus et al., 2006). The differences in relative abundance of each biomarker group in the treated microcosms may be related to differences in carbon metabolic versatility. If this is correct, Desulfobacter biomarkers were constantly present at steady relative abundances both in controls and ciprofloxacin treatments reflecting the microorganisms' ability to use acetate, a common metabolite of many anaerobic metabolic pathways. Desulfobulbus' metabolic versatility may have allowed it to more easily assimilate complex carbon substrates available, including ciprofloxacin. Desul- fovibrio did not immediately appear to respond to higher carbon availability and this may be due to its lower abundance in the sediments. The dominating presence of Desulfobacter biomarkers in all controls, with a low abundance of Desulfobulbus and no evidence of Desulfovibrio is consistent with SRB distribution reported previously in salt marshes. Desulfobacteriaceae associated sequences accounted for over $80 \%$ of the recovered sequences, while less than $1 \%$ out of 1650 sequences were assigned to Desulfovibrio in a salt marsh study (Klepac-Ceraj et al., 2004). The dominance of Desulfobacteriaceae in salt marsh communities has also been confirmed by other groups (Devereux et al., 1996; Rooney-Varga et al., 1998). Desulfovibrio, Desulfobacter and Desulfobulbus accounted for up to $30 \%$ of the bacterial RNA present in sediment influences by Spartina alterniflora in marsh sediments (Hines et al., 1999), and of this, Desulfobac- 
teriaceae accounted for approximately $25 \%$ of total bacterial RNA with minimal contribution from Desulfobulbus and Desulfovibrio $(1 \%-2 \%$ of total bacterial RNA). Overall, the SRB biomarkers indicate a shift from an acetate-utilizing microbial community (dominated by Desulfobacter), to a community capable of using a more complex carbon substrates. There are limited studies of the selective effects of ciprofloxacin on sulfate reducers. However, published reports indicate resistance in some clinical Desulfovibrio (McDougall et al., 1997), and no change in gut SRB number in rats treated with ciprofloxacin (Ohge et al., 2003). Our results suggest that ciprofloxacin had no apparent negative effects on SRB biomass or richness (as measured by PLFA) in anaerobic sediments.

Changes in microbial community composition indicated that the magnitude of ciprofloxacin effects was inversely correlated with the degree of sorption of ciprofloxacin to the sediments. Ciprofloxacin, and fluoroquinolones, in general have been shown to strongly sorb to soils and sediments, particularly clays (Nowara et al., 1997; Giger et al., 2003; Cardoza et al., 2005), thus potentially reducing the bioavailability and antibiotic potency of ciprofloxacin (Halling-Sørensen et al., 2003). These findings are consistent with our results, where the magnitude of the microbial community shift was smaller in SM, in which ciprofloxacin had the highest sorption potential, than in other sediments. However, the differences between controls and treatments demonstrate that even with sorption, the antibiotic is capable of modifying the microbial community.

We have shown that ciprofloxacin is capable of modifying microbial community composition at concentrations as low as $20 \mu \mathrm{g} \mathrm{ml}^{-1}$ in anaerobic sediments. GN bacteria, including Desulfovibrio, Desulfobulbus and Desulfobacter, appeared more resilient to the effects of ciprofloxacin than did GP bacteria. Effects were evident despite the fact that the concentration actually available to microorganisms was likely even lower due to substantial sorption to sediments (an estimated 80\%-90\% sorbed). Despite the fact that ciprofloxacin is a wide-spectrum antibiotic, its impact on sediment microbial communities was selective and favored SRB. As human impacts on the environment increase with expanding populations and growing use of medications, it is crucial to understand whether changes such as those observed in our study are evident in nature and what are the consequences for ecosystem microbial processes of these changes.

\section{Acknowledgements}

This research was supported in part by the CONACyT and UCMexus programs and UC Toxic Substances Research and Teaching Program. Additional support was provided by a grant from the US Environmental Protection Agency's
Science to Achieve Results (STAR) Estuarine and Great Lakes (EaGLe) Coastal Initiative through funding to the Pacific Estuarine Ecosystem Indicator Research (PEEIR) Consortium, US EPA Agreement EPA/R-82867601 and by Grant number 5 P42 ES04699 from the National Institute of Environmental Health Sciences, NIH. Its contents are solely our responsibility and do not necessarily represent the official views of the NIEHS, NIH.

\section{References}

Berlanga M, Montero MT, Hernandez-Borrell J, Vinas M. (2004). Influence of the cell wall on ciprofloxacin susceptibility in selected wild-type Gram-negative and Gram-positive bacteria. Int $J$ Antimicrob Agents 23: $627-630$.

Bila DM, Dezotti M. (2003). Pharmaceutical drugs in the environment. Quimica Nova 26: 523-530.

Bossio DA, Scow KM. (1998). Impacts of carbon and flooding on soil microbial communities: phospholipid fatty acid profiles and substrate utilization patterns. Microb Ecol 35: 265-278.

Bossio DA, Scow KM, Gunapala N, Graham KJ. (1998). Determinants of soil microbial communities: effects of agricultural management, season, and soil type on phospholipid fatty acid profiles. Microb Ecol 36: 1-12.

Boyd GR, Reemtsma H, Grimm DA, Mitra S. (2003). Pharmaceuticals and personal care products (PPCPs) in surface and treated waters of Louisiana, USA and Ontario, Canada. Sci Total Environ 311: 135-149.

Cardoza LA, Knapp CW, Larive CK, Belden JB, Lydy M, Graham DW. (2005). Factors affecting the fate of ciprofloxacin in aquatic field systems. Water Air Soil Pollution 161: 383-398.

Córdova-Kreylos AL, Cao YP, Green PG, Hwang HM, Kuivila KM, LaMontagne MG et al. (2006). Diversity, composition, and geographical distribution of microbial communities in california salt marsh sediments. Appl Environ Microbiol 72: 3357-3366.

Cunha BA, Qadri SMH, Ueno Y, Walters EA, Domenico P. (1997). Antibacterial activity of trovafloxacin against nosocomial Gram-positive and Gram-negative isolates. J Antimicrob Chemother 39: 29-34.

Dalhoff A, Schmitz FJ. (2003). In vitro antibacterial activity and phamacodynamics of new quinolones. Eur J Clin Microbiol Infect Dis 22: 203-221.

Datamonitor (2004). Fluoroquinolones, Established Products Drive Market Growth. [On-line]URL http:// www.piribo.com/publications/prescription_drugs/ DAT063.html.

Daughton CG. (2000). Pharmaceuticals in the environment: Overarching issues and concerns. Abs Papers ACS 219: U622.

Daughton CG, Ternes TA. (1999). Pharmaceuticals and personal care products in the environment: agents of subtle change? Environ Health Perspect 107: 907-938.

Devereux R, Hines ME, Stahl DA. (1996). S cycling: Characterization of natural communities of sulfatereducing bacteria by $16 \mathrm{~S}$ rRNA sequence comparisons. Microb Ecol 32: 283-292.

Eshel G, Levy GJ, Mingelgrin U, Singer MJ. (2004). Critical evaluation of the use of laser diffraction for particlesize distribution analysis. SSSA J 68: 736-743. 
Fernandes PB. (1988). Mode of action, and in vitro and in vivo activities of the fluoroquinolones. J Clin Pharmacol 28: 156-168.

Figueroa RA, Leonard A, Mackay AA. (2004). Modeling tetracycline antibiotic sorption to clays. Environ Sci Technol 38: 476-483.

Frostegård A, Tunlid A, Bååth E. (1991). Microbial biomass measured as total lipid phosphate in soils of different organic content. I Microbiol Methods 14: 151-163.

Giger W, Alder AC, Golet EM, Kohler HPE, McArdell CS, Molnar E et al. (2003). Occurrence and fate of antibiotics as trace contaminants in wastewaters, sewage sludges, and surface waters. Chimia 57: 485-491.

Golet EM, Xifra I, Siegrist H, Alder AC, Giger W. (2003). Environmental exposure assessment of fluoroquinolone antibacterial agents from sewage to soil. Environ Sci Technol 37: 3243-3249.

$\mathrm{Gu}$ C, Karthikeyan KG. (2005). Sorption of the antimicrobial ciprofloxacin to aluminum and iron hydrous oxides. Environ Sci Technol 39: 9166-9173.

Halling-Sorensen B. (2000). Algal toxicity of antibacterial agents used in intensive farming. Chemosphere 40: 731-739.

Halling-Sørensen B, Sengelov G, Ingerslev F, Jensen LB. (2003). Reduced antimicrobial potencies of oxytetracycline, tylosin, sulfadiazin, streptomycin, ciprofloxacin, and olaquindox due to environmental processes. Arch Environ Contam Toxicol 44: 7-16.

Halling-Sørensen B, Nielsen SN, Lanzky PF, Ingerslev F, Lutzhoft HCH, Jorgensen SE. (1998). Occurrence, fate and effects of pharmaceutical substances in the environment-A review. Chemosphere 36: 357-394.

Hines ME, Evans RS, Genthner BRS, Willis SG, Friedman S, Rooney-Varga JN et al. (1999). Molecular phylogenetic and biogeochemical studies of sulfate-reducing bacteria in the rhizosphere of Spartina alterniflora. Appl Environ Microbiol 65: 2209-2216.

Hooper DC. (1999). Mode of action of fluoroquinolones. Drugs 58: 6-10.

Hwang HM, Green PG, Young TM. (2006a). Tidal salt marsh sediment in California, USA. Part 1: occurrence and sources of organic contaminants. Chemosphere 64: 1383-1392.

Hwang HM, Green PG, Higashi RM, Young TM. (2006b). Tidal salt marsh sediment in California, USA. Part 2: occurrence and anthropogenic input of trace metals. Chemosphere 64: 1899-1909.

Kieft TL, Ringelberg DB, White DC. (1994). Changes in ester-linked phospholipid fatty-acid profiles of subsurface bacteria during starvation and desiccation in a porous-medium. Appl Environ Microbiol 60: 3292-3299.

Kieft TL, Wilch E, Oconnor K, Ringelberg DB, White DC. (1997). Survival and phospholipid fatty acid profiles of surface and subsurface bacteria in natural sediment microcosms. Appl Environ Microbiol 63: 1531-1542.

Klepac-Ceraj V, Bahr M, Crump BC, Teske AP, Hobbie JE, Polz MF. (2004). High overall diversity and dominance of microdiverse relationships in salt marsh sulphatereducing bacteria. Environ Microbiol 6: 686-698.

Kolpin DW, Furlong ET, Meyer MT, Thurman EM, Zaugg SD, Barber LB et al. (2002). Pharmaceuticals, hormones, and other organic wastewater contaminants in US streams, 1999-2000: a national reconnaissance. Environ Sci Technol 36: 1202-1211.
Lewin CS, Morrissey I, Smith JT. (1991). The mode of action of quinolones-the paradox in activity of low and high-concentrations and activity in the anaerobic environment. Eur J Clin Microbiol Infect Dis 10: 240-248.

Lin CE, Deng YJ, Liao WS, Sun SW, Lin WY, Chen CC. (2004). Electrophoretic behavior and pK(a) determination of quinolones with a piperazinyl substituent by capillary zone electrophoresis. J Chromatogr A 1051: 283-290.

Macalady JL, Mack EE, Nelson DC, Scow KM. (2000). Sediment microbial community structure and mercury methylation in mercury-polluted Clear Lake, California. Appl Environ Microbiol 66: 1479-1488.

MacKay AA, Figueroa RA. (2004). Mechanisms of antibiotic sorption to agricultural soils. Abs Papers ACS 228: U641.

MacKay AA, Figueroa RA, Seremet DE, Vasudevan D. (2004). Sorption of antibiotics to soils. Abs Papers ACS 228: U634.

McDougall R, Robson J, Paterson D, Tee W. (1997). Bacteremia caused by a recently described novel Desulfovibrio species. J Clin Microbiol 35: 1805-1808.

Miao XS, Bishay F, Chen M, Metcalfe CD. (2004). Occurrence of antimicrobials in the final effluents of wastewater treatment plants in Canada. Environ Sci Technol 38: 3533-3541.

Morrissey I, George JT. (2001). Measurement of the bactericidal activity of fluoroquinolones against Streptococcus pneumoniae using the bactericidal index method. Int J Antimicrob Agents 17: 33-37.

Nowara A, Burhenne J, Spiteller M. (1997). Binding of fluoroquinolone carboxylic acid derivatives to clay minerals. J Agric Food Chem 45: 1459-1463.

Ohge H, Furne JK, Springfield J, Sueda T, Madoff RD, Levitt MD. (2003). The effect of antibiotics and bismuth on fecal hydrogen sulfide and sulfatereducing bacteria in the rat. FEMS Microbiol Lett 228: 137-142.

Rabus R, Hansen T, Widdel F. (2006). Dissimilatory sulfateand sulfur-reducing prokaryotes. In: Dworkin M, Falkow S, Rosenberg E, Schleifer K-H and Stackebrandt E (eds). The Prokaryotes: Ecophysiology and Biochemistry. Springer New York: New York, NY, USA.

Ramos JL, Duque E, Gallegos MT, Godoy P, RamosGonzalez MI, Rojas A et al. (2002). Mechanisms of solvent tolerance in Gram-negative bacteria. Annu Rev Microbiol 56: 743-768.

Rao PSC, Bellin CA, Brusseau ML. (1993). Coupling biodegradation of organic chemicals to sorption and transport in soils and aquifers: paradigms and paradoxes. In: Chang FH (ed). Sorption and Degradation of Pesticides and Organic Chemicals in Soil. Soil Sci Soc Amer: Madison, WI, USA, pp 1-26.

Renew JE, Huang CH. (2004). Simultaneous determination of fluoroquinolone, sulfonamide, and trimethoprim antibiotics in wastewater using tandem solid phase extraction and liquid chromatography-electrospray mass spectrometry. J Chromatogr A 1042: 113-121.

Rooney-Varga JN, Genthner BRS, Devereux R, Willis SG, Friedman SD, Hines ME. (1998). Phylogenetic and physiological diversity of sulphate-reducing bacteria isolated from a salt marsh sediment. Syst Appl Microbiol 21: 557-568.

Seremet DE, MacKay AA. (2003). Sorption of ciprofloxacin and its substructures to pure clay. Abs Papers ACS 226: U488. 
Sparks DL (ed). (1996). Methods of Soil Analysis-Part 3: Chemical Methods. Soil Science Society of America Book Series, no. 5. Wisconsin: Madison.

Stein GE, Goldstein EJC. (2006). Fluoroquinolones and anaerobes. Clin Infect Dis 42: 1598-1607.

Tolls J. (2001). Sorption of veterinary pharmaceuticals in soils: a review. Environ Sci Technol 35: 3397-3406.

White DC, Davis WM, Nickels JS, King JD, Bobbie RJ. (1979). Determination of the sedimentary microbial biomass by extractable lipid phosphate. Oecologia 40: $51-62$.
Wilson BA, Smith VH, Denoyelles F, Larive CK (2003). Effects of three pharmaceutical and personal care products on natural freshwater algal assemblages. Environ Sci Technol 37: 1713-1719.

Zabinski RA, Walker KJ, Larsson AJ, Moody JA, Kaatz GW, Rotschafer JC. (1995). Effect of aerobic and anaerobic environments on antistaphylococcal activities of 5 fluoroquinolones. Antimicrob Agents Chemother 39: 507-512.

Zuccato E, Calamari D, Natangelo M, Fanelli R. (2000). Presence of therapeutic drugs in the environment. Lancet 355: 1789-1790. 